\title{
Communication
}

\section{SERS Biosensor Based on Engineered 2D-Aperiodic Nanostructure for In-Situ Detection of Viable Brucella Bacterium in Complex Matrix}

\author{
Massimo Rippa ${ }^{1,+}$, Riccardo Castagna $^{1,+}{ }^{\dagger}$ Domenico Sagnelli ${ }^{1,+}$, Ambra Vestri ${ }^{1, *}+\oplus$, Giorgia Borriello ${ }^{2} \mathbb{D}$, \\ Giovanna Fusco ${ }^{1,2}$, Jun Zhou ${ }^{3}$ and Lucia Petti ${ }^{1, *}$ \\ 1 Institute of Applied Sciences and Intelligent Systems "E. Caianiello" of CNR, 80078 Pozzuoli, Italy; \\ massimo.rippa@isasi.cnr.it (M.R.); riccardo.castagna@isasi.cnr.it (R.C.); domenico.sagnelli@isasi.cnr.it (D.S.); \\ giovanna.fusco@izsmportici.it (G.F.) \\ 2 Istituto Zooprofilattico Sperimentale del Mezzogiorno (IZSM), 80055 Portici, Italy; \\ giorgia.borriello@cert.izsmportici.it \\ 3 Institute of Photonics, Faculty of Science, Ningbo University, Ningbo 315211, China; zhoujun@nbu.edu.cn \\ * Correspondence: ambra.vestri@isasi.cnr.it (A.V.); lucia.petti@isasi.cnr.it (L.P.) \\ + Authors contributed equally.
}

check for

updates

Citation: Rippa, M.; Castagna, R.; Sagnelli, D.; Vestri, A.; Borriello, G.; Fusco, G.; Zhou, J.; Petti, L. SERS Biosensor Based on Engineered 2D-Aperiodic Nanostructure for In-Situ Detection of Viable Brucella Bacterium in Complex Matrix. Nanomaterials 2021, 11, 886. https:// doi.org/10.3390/nano11040886

Academic Editor: Sharmila M. Mukhopadhyay

Received: 4 March 2021

Accepted: 27 March 2021

Published: 31 March 2021

Publisher's Note: MDPI stays neutral with regard to jurisdictional claims in published maps and institutional affiliations.

Copyright: (c) 2021 by the authors. Licensee MDPI, Basel, Switzerland. This article is an open access article distributed under the terms and conditions of the Creative Commons Attribution (CC BY) license (https:/ / creativecommons.org/licenses/by/ $4.0 /)$.

\begin{abstract}
Brucella is a foodborne pathogen globally affecting both the economy and healthcare Surface Enhanced Raman Spectroscopy (SERS) nano-biosensing can be a promising strategy for its detection. We combined high-performance quasi-crystal patterned nanocavities for Raman enhancement with the use of covalently immobilized Tbilisi bacteriophages as high-performing bio-receptors. We coupled our efficient SERS nano-biosensor to a Raman system to develop an on-field phage-based bio-sensing platform capable of monitoring the target bacteria. The developed biosensor allowed us to identify Brucella abortus in milk by our portable SERS device. Upon bacterial capture from samples $\left(10^{4}\right.$ cells), a signal related to the pathogen recognition was observed, proving the concrete applicability of our system for on-site and in-food detection.
\end{abstract}

Keywords: quasi-crystals; nano-biosensing; SERS; nanocavities; bacteria

The contamination of food and drinks with pathogenic bacteria is a problem affecting both the economy and healthcare. Brucella abortus is a central example of this problem because it is among the main zoonosis affecting the global economy [1]. It infects livestock and wild-life animals, resulting in loss of reproductive efficiency and abortion [2]; moreover, it is transmitted to humans by ingestion of contaminated food.

The gold standard method for the diagnosis of Brucella is blood culture, but this method is characterized by different drawbacks [3], not last the long time required for cell cultivation. Serological tests, including the agglutination test to detect the antilipopolysaccharide (LPS) O-antigen antibodies, are also available but are characterized by poor specificity due to structural similarities among different bacteria [4,5].

The control of Brucellosis is of prime importance in the endemic areas of poor countries, and the salubrity of animal source foods, in particular milk, is crucial to avoid the transmission of this disease from livestock to man [6]. The availability of simple and affordable tests to detect the pathogen presence in food of animal origin can therefore represent an important instrument to limit human outbreaks. Efficient analyses for the detection of Brucella are already available but not without important compromises: They are usually time-consuming, costly, and unsuitable for the on-site pathogen detection [2,7-9]. Highsensitivity polymerase chain reaction (PCR)-based and enzyme-linked immunosorbent assay (ELISA) methods are important examples of culture-free methods, but despite their great specificity and sensitivity, they are time-consuming and still suffering from operational simplicity [8,9]. Electrochemical Impedance Spectroscopy (EIS) is another method 
that has been recently employed for the Brucella melitensis [10] detection; however, EIS often demonstrates insufficient selectivity [11]. New attempts are therefore ongoing to develop a reliable, fast, and on-site method for Brucella detection [12,13].

A very promising approach to address this problem is the use of optical biosensors. Over the last decade, the combined efforts of the scientific community have driven the technological advancement towards high-performing, versatile, and compact optical devices [14] for industrial and point-of-care applications [15-17].

Among the different spectroscopy strategies employed to develop high-performance biosensing, Surface Enhanced Raman Spectroscopy (SERS) certainly offers appealing advantages. SERS is a label-free transduction method that exploits the plasmonic properties of metal nanomaterials (Localized Surface Plasmon Resonance, LSPR) to enhance the scattered Raman signal of several magnitudes [18] with reproducible and reliable features [13,17-21]. The possibility to define a SERS fingerprint spectrum for the specific identification of an analyte, from small molecules up to whole cells, is surely remarkable [22,23]. The SERS sensitivity and specificity can therefore allow a short time and effective detection of the pathogen, bypassing the need for cultures or multistep procedures.

A limiting factor of SERS-based sensors is the intrinsic loss of specificity in complex matrices that hampers their applicability and commercial distribution. The most promising strategy used in the literature to overcome this problem is the creation of a receptor layer specific for the analyte of interest. Antibodies are commonly used as receptors of biosensors, even suffering from natural sensitivity to variable operating conditions and being very expensive. A novel and workable alternative to antibodies is the use of bacteriophage viruses able to bind the organism in study. Bacteriophages not only present an excellent specificity for the host bacteria, but they are also characterized by a remarkable tolerance against critical conditions (e.g., organic solvent, extreme temperatures) [24]. Phages are viruses that can specifically infect the target host bacteria and utilize its replicative machinery to produce the progeny phages. The specific recognition and binding to the host bacteria occurs via phage tail fibres and baseplate [25]. The specificity of this phage-bacteria bond can be also higher than antibodies and other bioreceptors commonly used to detect pathogens such as aptamers and antimicrobial peptides. Moreover, phages are characterized by lower costs and can be cultured in adequately equipped microbiological laboratories. In particular, the Tbilisi bacteriophage specifically recognizes B. abortus and it has been used for decades for Brucella species identification in the diagnosis and epidemiology of brucellosis [26].

We already successfully showed the feasibility of our SERS nanosensors for Brucella analysis [12] and the quality of the achieved results encouraged us to further explore the efficiency of our technology for the detection of the live pathogen in real food samples.

In this communication, we explored a new optimized approach in which a sensitive deterministic aperiodic nanocavity (DANC) patterned gold layer was covalently functionalized with Tbilisi $(\mathrm{Tb})$ bacteriophages via diazo-coupling for a detection of the Brucella abortus in a food matrix. The developed sensor was also used to detect the viable form of Brucella abortus in milk by a portable SERS device of our creation [12] (Figure 1).

In recent times, different SERS sensors have been developed using metallic nanopatterned surfaces to reveal weak Raman scattering bio-specimen in low concentration ranges $[27,28]$. These nanomaterials are distinguished not only by the noble metal used but also by the pattern features. Indeed, the structure-dependent SERS enhancement is linked to the size, geometry, symmetry, and order of the nanopatterned structure.

In particular, quasi-crystal $\mathrm{Au}$ nanocavities (NCs) arranged in Thue-Morse array (ThMo) were chosen for the realisation of the SERS-based sensor. ThMo aperiodic geometry is generated by the iterative substitution rule: $A \rightarrow A B, B \rightarrow B A$ that can be extended to two dimensions [29]. Optical properties of the ThMo nanopattern have been widely investigated and their peculiarities (singular continuous Fourier/Diffraction spectra, self-similar hierarchy of pseudoband-gap regions, omnidirectional reflectivity, and light emission enhancement) make such geometries attractive candidates for the realization of high-performance plasmonic nanosensors [23,30-36]. Despite the greater difficulty of 
both design and fabrication that they require compared to conventional periodical pattern, aperiodic arrangements show important advantages for the realization of sensing systems. As reported in the literature, they provide the necessary balance between their resonant modes and the spatial distribution of large field intensity over extended sensing areas, resulting in largely improved sensitivity respect to periodic crystals cavities, which are limited by the small overlap of the analyte with localized field [37]. Due to the higher structural disorder, the aperiodic arrays are strongly coupled in both the plasmonic near field regime (short-range coupling) and the photonic diffractive one (long-range coupling), resulting in strong in-plane multiple light scattering [38]. This enhanced scattering enables both field states that are spatially distributed over larger array areas and much longer photon dwelling times with the sensing layer compared to periodic plasmonic structures in which scattered photons easily (and faster) escape from the substrate. These characteristics improve the light-analyte interaction, enhancing the sensitivity of the system and making these types of patterns promising to develop advanced sensing devices.

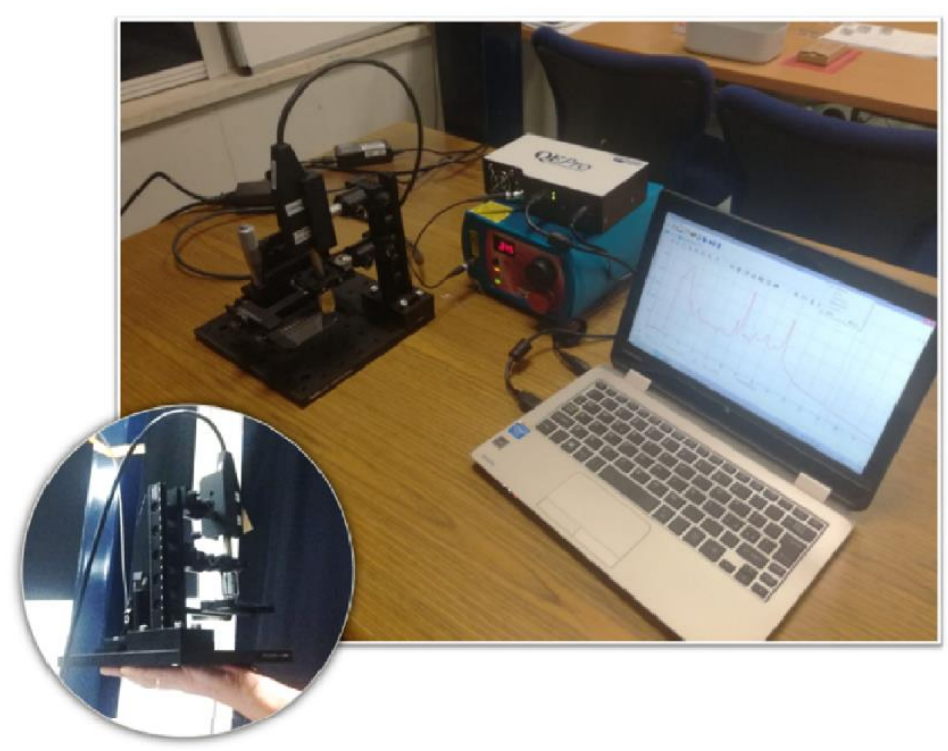

(a)

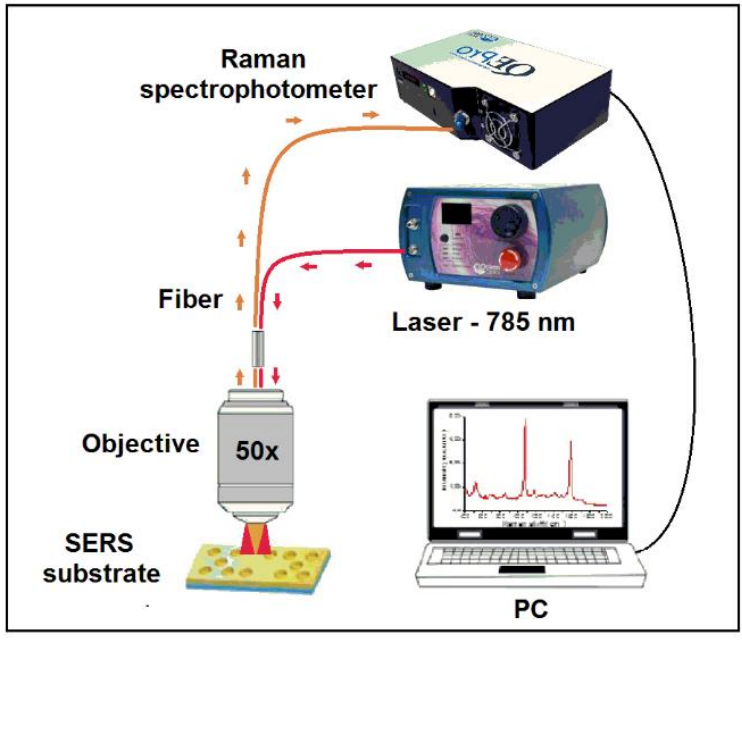

(b)

Figure 1. Home-made portable system for Surface Enhanced Raman Spectroscopy (SERS) analysis in situ: (a) Picture of the system, (b) schematic representation.

The procedure followed for the nanofabrication was previously described in the literature [39] and used here with some modifications detailed below. The plasmonic metastructures with squar-shaped NCs based on a 10th-order ThMo array were fabricated by a high-resolution electron beam lithography (EBL) system (Raith 150 EBL system by Raith GmbH, Dortmund, Germany), using ZEP 520A (Marubeni Europe plc, London, UK) as positive resist (100 nm layer). The resist was spin-coated on a $15 \mathrm{~nm}$ conductive ITO coated glass substrate, baked at $170{ }^{\circ} \mathrm{C}$ for $5 \mathrm{~min}$, and exposed to a $10.2 \mathrm{pA}$ electron beam with an area dose of $27 \mu \mathrm{C} / \mathrm{cm}^{2}$. After the development [40], a $50 \mathrm{~nm}$ gold layer was evaporated on the ZEP surface by e-beam process (SISTEC CL-400C e-beam evaporator by SISTEC, Milan, Italy). The produced quasi-crystal pattern was characterized by square NCs having a minimum distance of $\mathrm{a}=50 \mathrm{~nm}$, and a side size of $\mathrm{d}=185 \mathrm{~nm}[23,39]$ with increasing edge-to-edge distances from 25 to $100 \mathrm{~nm}$ in a two-layer (ZEP/ Au) configuration.

After the realisation of the metastructures (Figure 2), the sensors were morphologically characterized using scanning electron microscopy (SEM) (Figure 3). The analysis of micropictures allowed us to confirm the conformity in shape and size of the NCs produced. 

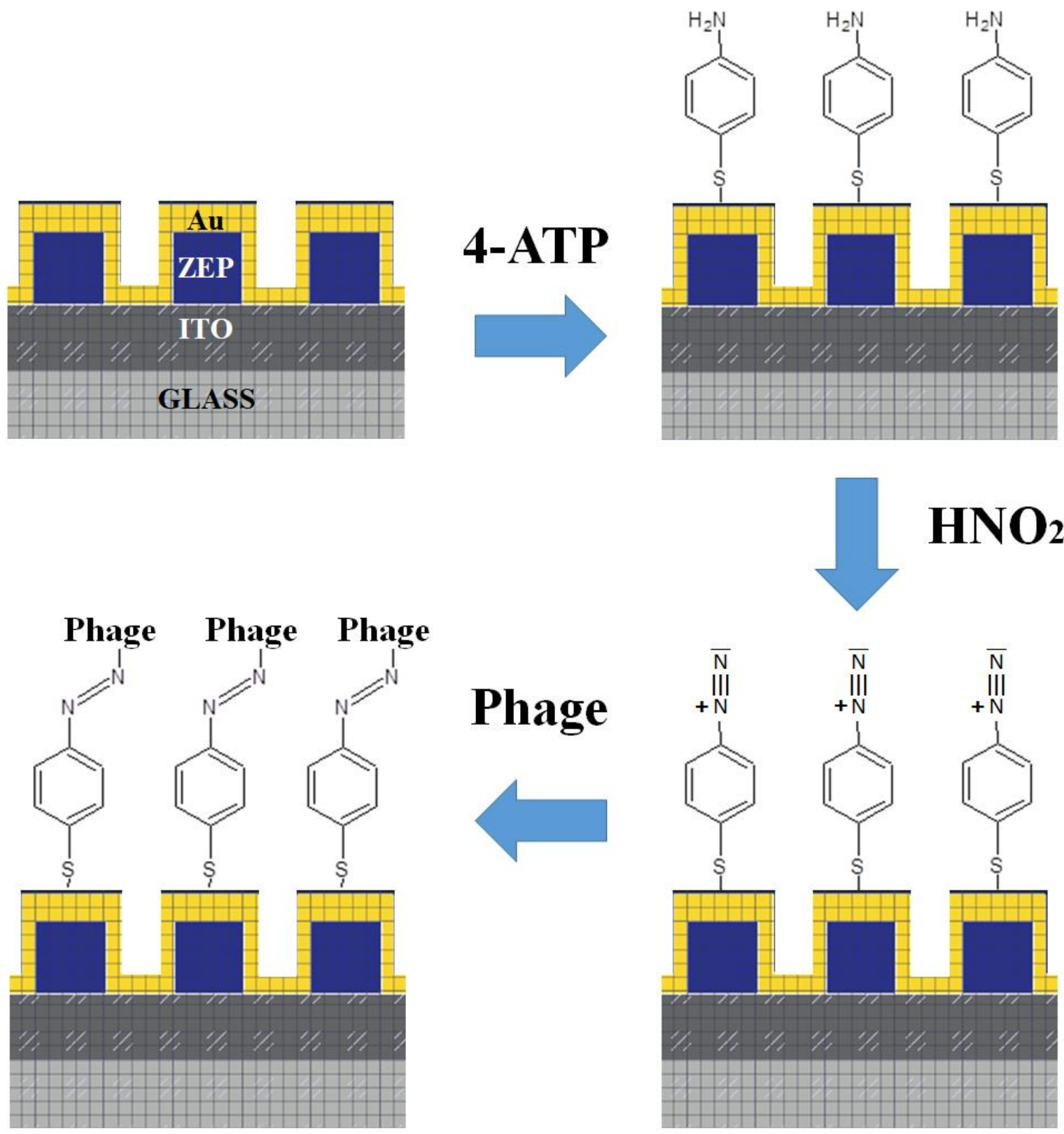

Figure 2. Schematic representation of the patterned NCs and the Au-surface functionalization.

The sensor surface was then functionalized with the phages. Tb phages (LGC Standards) were propagated on Brucella abortus in a Bio-Safety Level 3 (BSL-3) facility, using a standard protocol [12]. In particular, Tb enumeration and propagation were carried out by the double layer agar method [41].

In order to immobilize the phages, a 4-aminothiophenol (4-ATP) self-assembled monolayer (SAM) was formed on the surface for the covalent binding of $\mathrm{Tb}$ via diazo-coupling, as previously reported [28]. Briefly, the diazo-coupling reaction was carried out with the support of an optical microscope in order to prevent damages to the nanostructures. After the complete covering of the gold nanosurface with micrograins of sodium nitrite, acidic acid was dropped on the sodium nitrite with a consequent production of nitrous acid $\left(\mathrm{HNO}_{2}\right)$ in the gaseous phase (bubble formation became visible on the chip surface). At last, a $10^{6} \mathrm{pfu} / \mathrm{mL}$ bacteriophage solution was added to the nanosurface and left in incubation overnight at room temperature. Several $\mathrm{ddH}_{2} \mathrm{O}$ washings were performed prior to air blow the chip and record the SERS spectra. 


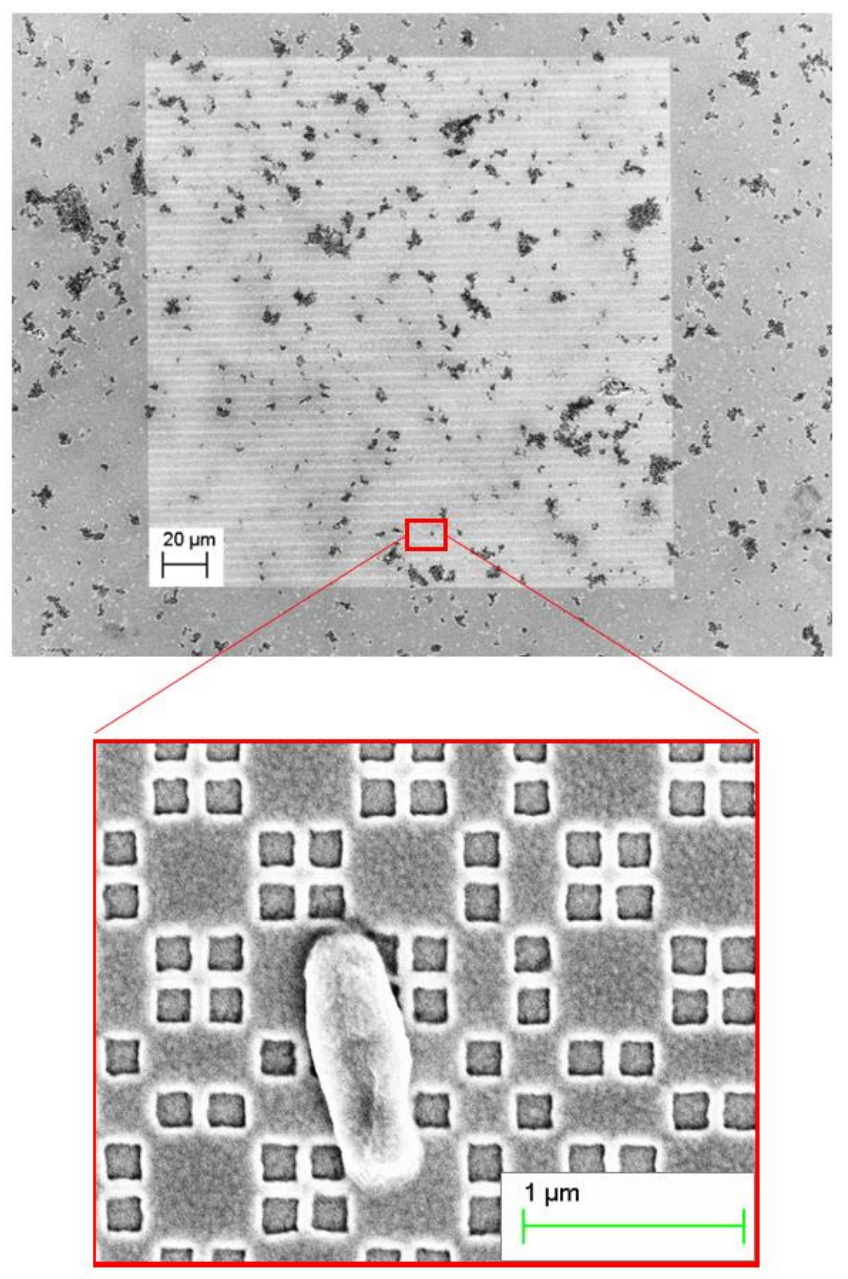

Figure 3. Morphological characterization of the nanostructures by SEM. Detailed image of the structure showing a cell of Brucella abortus is highlighted in red. Structure measures are distance of a $=50 \mathrm{~nm}$, and side size of $\mathrm{d}=185 \mathrm{~nm}$ with increasing edge-to-edge distances from 25 to $100 \mathrm{~nm}$.

Before the detection of the alive Brucella, an aqueous suspension of the bacterium inactivated via formaldehyde treatment was used to obtain a reference spectrum. Precisely, $300 \mu \mathrm{L}$ of Brucella abortus suspension $\left(10^{5} \mathrm{CFU} / \mathrm{mL}\right)$ in water was dropped on the phagefunctionalized nanostructures and they were left to react for $40 \mathrm{~min}$. The sensor surface was rinsed with $\mathrm{ddH}_{2} \mathrm{O}$ before SERS measurement so as to remove non-captured bacteria. SERS analysis was performed by coupling a Raman system (QE Pro-Raman system by Ocean Optics, Duiven, The Netherlands) with an upright microscope Olympus BX51 (Olympus, Southend-on-Sea, England) in a backscattering configuration (Figure 1), and the spectra were collected in the range $400-2000 \mathrm{~cm}^{-1}$ (10 s acquisition time, $50 \times$ microscope objective with N.A. 0.75 and a laser power of $12 \mathrm{~mW}$ ) [12]. Mean spectra were calculated from repeated measurements on different points of the sensor and on its different replicas.

Afterwards, we worked in a BSL-3 laboratory with alive Brucella cells suspended both in water and in milk $\left(10^{5} \mathrm{CFU} / \mathrm{mL}\right)$. In particular, the contaminated sample $(300 \mu \mathrm{L})$ was incubated on the sensor for $40 \mathrm{~min}$ and then washed away with $\mathrm{ddH}_{2} \mathrm{O}$. The spectra were recorded on site (in the BSL-3 facility) using an optimized homemade portable Raman prototype [12].

In order to obtain an optical sensor suitable for the pathogen detection, we chose to exploit as metastructure the ThMo distribution, whose potential for sensing was already demonstrated $[23,36,39]$. In our previous work, we studied the plasmonic properties of ThMo-arranged NCs by Finite Difference in Time Domain (FDTD) simulations suggesting a characteristic near-field with a high spatial density of hot-spots [31]. Moreover, we 
demonstrated that a sensor patterned with such geometry and functionalized with 4-ATP significantly enhanced the whole spectrum of a model protein (Bovine Serum AlbuminBSA) [39]. 4-ATP is an ideal solution for the functionalisation of SERS sensors, as it is indeed an aromatic thiol able to generate well-characterized Raman bands. 4-ATP can bind the gold surface with its -SH group, forming a SAM, while the primary amine can be exploited to covalently bind receptor-like bio-molecules [42].

The EF of the fabricated ThMo SERS sensor functionalized with 4-mercaptobenzoic acid (4-MBA) was calculated to evaluate the performance of the metastructure as reported in the literature [12]

$$
E F=\left(I_{S E R S} \times N_{R E F}\right) /\left(I_{R E F} \times N_{S E R S}\right),
$$

where $I_{S E R S}$ and $I_{R E F}$ are the intensities of the 4-MBA peak at $1076 \mathrm{~cm}^{-1}$ in the SERS spectrum and at $1084 \mathrm{~cm}^{-1}$ in the Raman spectrum, respectively. Similarly, $N_{S E R S}$ and $N_{R E F}$ are the number of 4-MBA molecules contributing to the SERS and the Raman signals [28]. We realized the measurements in a dry state and the estimated values were: $I_{\text {SERS }}=68320$ counts, $I_{R E F}=2720$ counts, $N_{S E R S}=1.44 \times 10^{6} \mathrm{~mol}$ and $N_{R E F}=2.2 \times 10^{11}$ mol, therefore achieving an average EF for our ThMo structure $[39,43]$ of $3.8 \times 10^{6}$ that suited our purpose of microorganism detection. EF $>10^{6}$ are indeed adequate to reveal Brucella at the single-cell level in aqueous suspension, as reported by Rippa et al. [12].

For the specific capture of the pathogen, the 4-ATP modified sensor was further functionalized with the bacteriophage $\mathrm{Tb}$ (Podoviridae family) via diazotization. The diazotization, also known as azo coupling, is an electrophilic aromatic substitution between a nucleophilic arene and a diazonium cation (i.e., the electrophile) to generate an azocompound. In this case, the diazonium $(4-\mathrm{ATP}-\mathrm{N} \equiv \mathrm{N}+)$ is formed by the reaction of the 4-ATP primary amine with the nitrous acid. The following conjugation of $\mathrm{Tb}$ to the diazonium takes place through the phage histidine/tyrosine residues that can act as nucleophiles [42]. After the diazo bond formation, well-distinguishable vibrations [28,42] appeared in the SERS spectrum. In particular, the comparison between the 4-ATP SERS spectrum (green line, Figure $4 \mathrm{a}$ ) and the other spectra reported in Figure $4 \mathrm{a}$ (diazonium spectrum, blue curve; covalently immobilized phage, black curve; captured Brucella, red curve) allowed us to clearly note the presence of a new peak at $1322 \mathrm{~cm}^{-1}$ related to the vibrational stretching of the diazo-bond (4-ATP-N=N-Tb) $[39,42]$. This peak at $1322 \mathrm{~cm}^{-1}$ represents a valuable SERS marker [28,42] and we used its area as reference. In particular, we calculated the area increase of this reference peak due to a binding event, as previously reported [28]. A remarkable 30-fold amplification of the reference peak after phage immobilization was estimated with respect to the diazonium (4-ATP-N $\equiv \mathrm{N}+$ ) spectrum (Figure $4 \mathrm{a}$ ).

At first, we detected the $B$. abortus presence in aqueous samples $\left(10^{5} \mathrm{CFU} / \mathrm{mL}\right)$, noticing an amplification of 1.3-fold for the peak located at $1322 \mathrm{~cm}^{-1}$ (red line, Figure $4 \mathrm{~b}$ and Table 1).

As previously reported in literature [44], the SERS is based on a very short-range phenomenon and it is possible to assess via SERS the complete Raman bands only for the chemical moieties closest to the gold nanosurface. For this reason, we were able to assess the diazonium (4-ATP-N $\equiv \mathrm{N}+$ ) SERS spectra but the successive binding events slightly affected the achieved Raman band pattern [44,45]. Binding events occurring on the diazonium $(4-\mathrm{ATP}-\mathrm{N} \equiv \mathrm{N}+$ ) layer were however detectable. Indeed, they resulted in changes in the signal enhancement, according to the literature $[12,44]$. The Raman enhancement was not exclusive for just a single peak of the spectrum (Table 1) $[12,39,44]$, but for convenience we chose the peak at $1322 \mathrm{~cm}^{-1}$ (related to the vibrational stretching of the diazo-bond) as a reference to evaluate the signal increment consequent to the binding. To facilitate the spectra comparison, the SERS spectra were referenced to the zero level and were normalized by setting the maximum intensity of the Brucella spectrum at 1 (as in Figure 4b). 


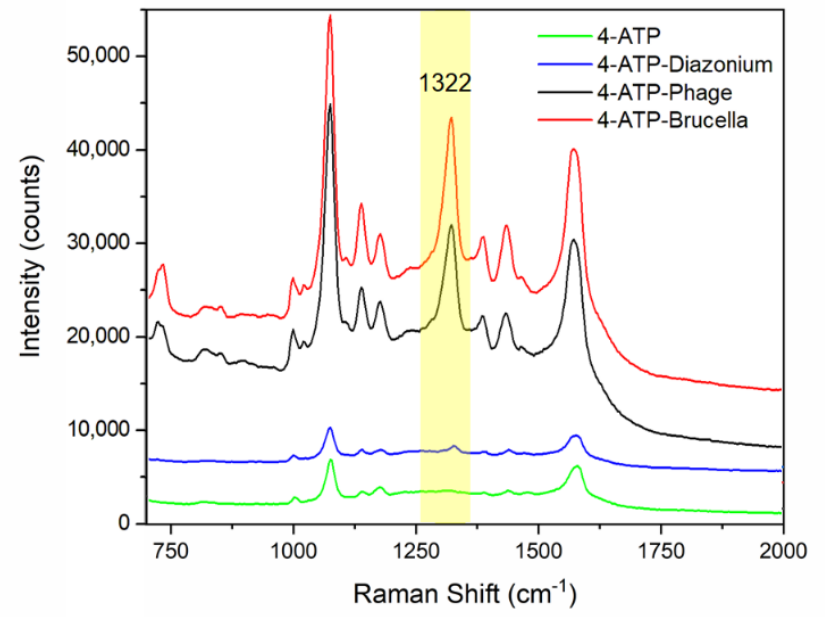

(a)

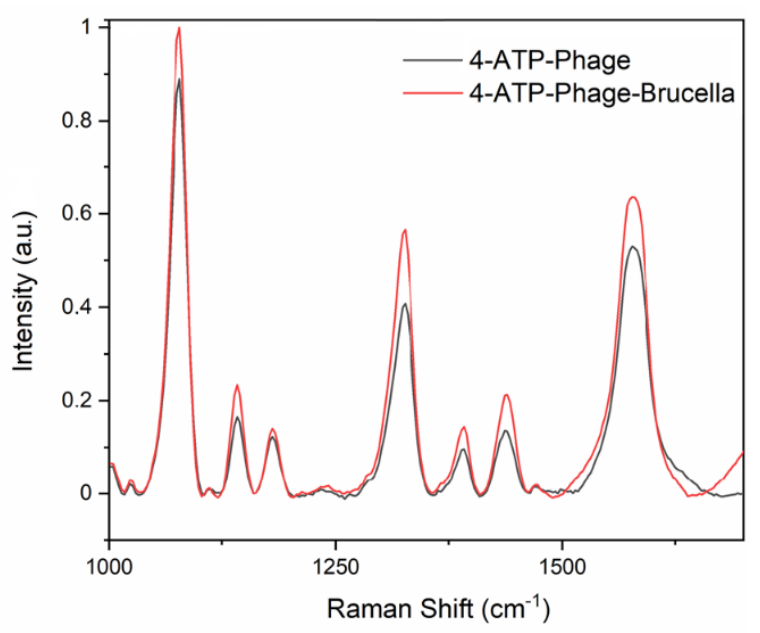

(b)

Figure 4. Comparison of SERS measurements performed on our functionalized nanostructures after binding in ddH $\mathrm{H}_{2} \mathrm{O}$. (a) Registered SERS spectra of the 4-ATP SAM (green line), the diazonium (4-ATP-N $\equiv \mathrm{N}+$ ) (blue curve), the covalently immobilized phage (black curve), and the captured Brucella (red curve). (b) Magnification of the SERS spectra referenced to the zero level for the covalently immobilized phage (black curve) and the captured Brucella (red curve).

Table 1. Vibrational assignment of Raman and SERS spectra.

\begin{tabular}{|c|c|c|c|c|c|}
\hline Vibrational Assignment & $\begin{array}{l}\text { 4-ATP Raman } \\
\left(\mathrm{cm}^{-1}\right)\end{array}$ & $\begin{array}{l}\text { 4-ATP SERS } \\
\left(\mathrm{cm}^{-1}\right)\end{array}$ & $\begin{array}{l}\text { Tb Phage } \\
\left(\mathrm{cm}^{-1}\right)\end{array}$ & $\begin{array}{c}\text { Brucella } \\
\text { Enhancement in } \\
\mathrm{ddH}_{2} \mathrm{O}^{1}\end{array}$ & $\begin{array}{c}\text { Brucella } \\
\text { Enhancement in } \\
\text { Milk }^{1}\end{array}$ \\
\hline $\mathrm{SC}$ str $+\mathrm{NH}_{2}$ rock & $1086 \mathrm{~s}$ & 1076 & $1075 \mathrm{~s}$ & 1.1 & 3.9 \\
\hline $\mathrm{CH}$ bend & 1174 w & 1177 & $1177 \mathrm{~m}$ & 1.1 & 3.8 \\
\hline $\mathrm{CN}$ bend & 1206 vw & - & - & - & - \\
\hline $\mathrm{CH}$ str & $1288 \mathrm{w}$ & 1308 & - & - & - \\
\hline NN str & - & - & $1322 \mathrm{~s}$ & 1.3 & 4 \\
\hline $\mathrm{CC}$ str $+\mathrm{CH}+$ rock $+\mathrm{NH}_{2}$ rock & - & 1391 & $1388 \mathrm{w}$ & 1.2 & 1.2 \\
\hline $\mathrm{CC}$ str $+\mathrm{NH}_{2}$ rock & - & 1440 & $1436 \mathrm{~m}$ & 1.5 & 0.8 \\
\hline $\mathrm{CC}$ str $+\mathrm{CH}$ bend & $1491 \mathrm{w}$ & 1478 & - & - & - \\
\hline $\mathrm{CC}$ str $+\mathrm{NH}_{2}$ bend & $1590 \mathrm{~s}$ & 1581 & $1574 \mathrm{~s}$ & 1.3 & 4.3 \\
\hline $\mathrm{SH}$ str & 2555 & - & - & - & - \\
\hline
\end{tabular}

${ }^{1}$ The areas of the fitted peaks were used to calculate the enhancement of the signal as compared to the negative control (phage signal without the bacteria).

The performances of our sensor were then tested analyzing the presence of live $B$. abortus cells $\left(10^{5} \mathrm{CFU} / \mathrm{mL}\right)$ in a food matrix, i.e., micro-filtrated milk (Figure 5).

We demonstrated that quasi-crystal patterned NCs functionalized with 4-ATP and Tb bacteriophage allowed the effective SERS detection of $\approx 10^{4}$ viable Brucella abortus cells from a reduced sample volume.

The presented SERS substrate had an EF of $3.8 \times 10^{6}$, suitable to reveal the microorganism at single-cell level [12], and a 4-fold intensity enhancement of the marker peak at $1322 \mathrm{~cm}^{-1}$ (vibrational stretching of 4-ATP-N=N-Tb) was observed for the bacterium detection in milk. Such performance was due to both the covalent $\mathrm{Tb}$ attachment to the sensor surface via diazotisation and the specific phage recognition of the pathogen.

These results indicated, for the first time to our best knowledge, that SERS spectroscopy in combination with ThMo metastructures and a 4-ATP-N=N-Tb functionalisation can offer a reliable and easy alternative for in situ detection of Brucella also in a real matrix such as milk. Work is in progress to detect the pathogen in clinical matrices for diagnostic purposes. 


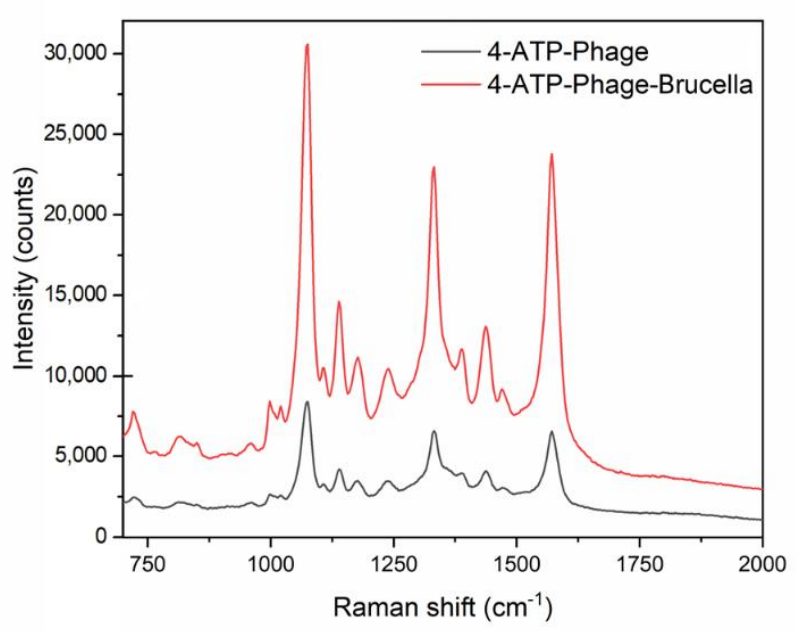

(a)

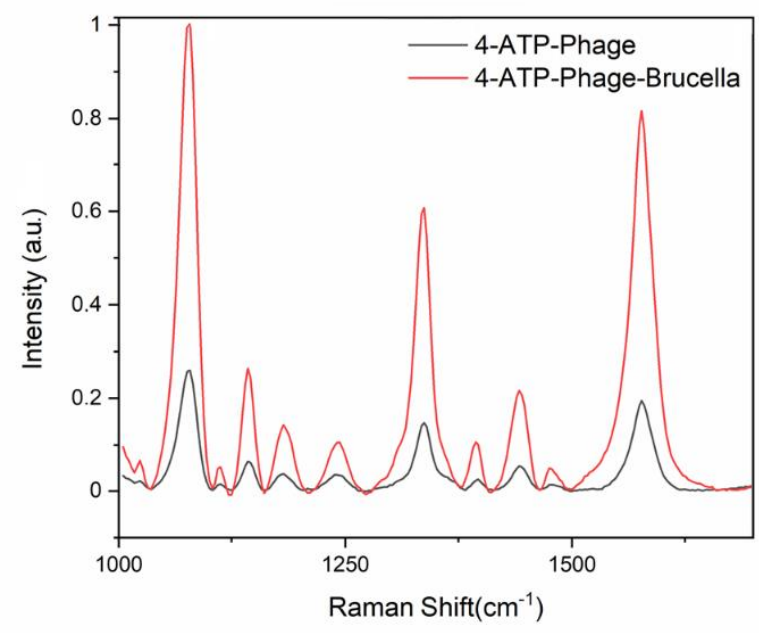

(b)

Figure 5. Comparison of SERS measurements performed on our functionalized nanostructures after binding in milk. (a) Registered SERS spectra of the covalently immobilized phage (black curve) and the captured Brucella. (b) Magnification of 40-min incubation of the Tb-sensor with milk free of pathogens (black line, Figure 5). Micro-filtrated milk was then inoculated with the live bacteria. The spiked sample $\left(300 \mu \mathrm{L}\right.$, total bacterial count of $\left.3 \times 10^{4} \mathrm{CFU}\right)$ was dispersed onto the biosensor surface and incubated for $40 \mathrm{~min}$. The $1322 \mathrm{~cm}^{-1}$ peak recorded for the contaminated sample (red line, Figure $5 \mathrm{~b}$ ) had a 4-fold larger area than the reference peak of the negative control spectrum (black line, Figure $5 \mathrm{~b}$ and Table 1 ). These results proved the outstanding performances of our biosensor in real conditions, i.e., with a viable form of the pathogen and a complex food matrix. Interesting to note, the signal amplification achieved for B. abortus detection in milk was even higher than in distilled water at equal bacterial count. A plausible reason for this discrepancy could lie in the $\mathrm{pH} /$ ionic strength values of the two environments that differently influenced the phage binding.

Author Contributions: The manuscript was written through contributions of all authors. + These authors contributed equally (match statement to author names with a symbol). Conceptualization, L.P. and J.Z.; methodology, R.C. and G.B.; validation, G.F.; investigation, M.R.; data curation, D.S. and A.V.; writing—original draft preparation, L.P., D.S. and A.V.; writing-review and editing, G.F., M.R., D.S., A.V., R.C. and L.P.; supervision, L.P. All authors have read and agreed to the published version of the manuscript.

Funding: Progetto FESR P.O.R. Campania 2007-2013-Bando sportello dell'innovazione-progetti di trasferimento tecnologico cooperativi e di prima industrializzazione per le imprese innovative ad alto potenziale, dal Titolo: "Kit for Brucella Abortus e B. Melitensis nano-Biosensing RApid detection (AMBRA)", CUP_B52I15004170002.

Informed Consent Statement: Not applicable.

Data Availability Statement: The data presented in this study are available on request from the corresponding author.

Acknowledgments: The authors would like to thank Rubina Paradiso form IZSM for her valuable advices and help. The authors would also like to thank Eugenia Bobeico from ENEA (Portici) for her support in gold evaporation processes.

Conflicts of Interest: The authors declare no conflict of interest.

\section{References}

1. McDermott, J.; Grace, D.; Zinsstag, J. Economics of Brucellosis Impact and Control in Low-Income Countries. OIE Rev. Sci. Tech. 2013, 32, 249-261. [CrossRef]

2. Redkar, R.; Rose, S.; Bricker, B.; DelVecchio, V. Real-Time Detection of Brucella Abortus, Brucella Melitensis and Brucella Suis. Mol. Cell. Probes 2001, 15, 43-52. [CrossRef] [PubMed]

3. Negròn, M.E.; Tiller, R. Centers for Disease Control and Prevention. CDC Yellow Book 2020: Health Information for International Travel; Chapter 4-Brucellosis; Oxford University Press: New York, NY, USA, 2017. 
4. Mccutcheon, K.; Bandara, A.B.; Zuo, Z.; Heflin, J.R.; Inzana, T.J. The Application of a Nanomaterial Optical Fiber Biosensor Assay for Identification of Brucella Nomenspecies. Biosensors 2019, 9, 64. [CrossRef] [PubMed]

5. Gupte, S.; Kaur, T. Diagnosis of Human Brucellosis. J. Trop. Dis. 2016, 4. [CrossRef]

6. O'Callaghan, D. Human Brucellosis: Recent Advances and Future Challenges. Infect. Dis. Poverty 2020, 9. [CrossRef]

7. Meisel, S.; Stöckel, S.; Elschner, M.; Melzer, F.; Rösch, P.; Popp, J. Raman Spectroscopy as a Potential Tool for Detection of Brucella Spp. in Milk. Appl. Environ. Microbiol. 2012, 78, 5575-5583. [CrossRef]

8. Hans, R.; Yadav, P.K.; Sharma, P.K.; Boopathi, M.; Thavaselvam, D. Development and Validation of Immunoassay for Whole Cell Detection of Brucella Abortus and Brucella Melitensis. Sci. Rep. 2020, 10. [CrossRef]

9. Projahn, M.; Hammerl, J.A.; Dieckmann, R.; Dahouk, S.A. A Proof of Principle for the Detection of Viable Brucella Spp. In Raw Milk by qPCR Targeting Bacteriophages. Microorganisms 2020, 8, 1326. [CrossRef]

10. Wu, H.; Zuo, Y.; Cui, C.; Yang, W.; Ma, H.; Wang, X. Rapid Quantitative Detection of Brucella melitensis by a Label-Free Impedance Immunosensor Based on a Gold Nanoparticle-Modified Screen-Printed Carbon Electrode. Sensors 2013, 13, 8551-8563. [CrossRef] [PubMed]

11. Amini, K.; Ebralidze, I.I.; Chanb, N.W.C.; Kraatz, H.-B. Characterization of TLR4/MD-2-modified Au sensor surfaces towards the detection of molecular signatures of bacteria. Anal. Methods 2016, 8, 7623-7631. [CrossRef]

12. Rippa, M.; Castagna, R.; Pannico, M.; Musto, P.; Borriello, G.; Paradiso, R.; Galiero, G.; Censi, S.B.; Zhou, J.; Zyss, J.; et al. Octupolar Metastructures for a Highly Sensitive, Rapid, and Reproducible Phage-Based Detection of Bacterial Pathogens by Surface-Enhanced Raman Scattering. ACS Sens. 2017, 2, 947-954. [CrossRef] [PubMed]

13. Chen, H.; Cui, C.; Ma, X.; Yang, W.; Zuo, Y. Amperometric Biosensor for Brucella Testing through Molecular Orientation Technology in Combination with Signal Amplification Technology. ChemElectroChem 2020, 7, 2672-2679. [CrossRef]

14. Vestri, A.; Margheri, G.; Landini, E.; Meacci, E.; Tiribilli, B. A Versatile and Compact Surface Plasmon Resonance Spectrometer Based on Single Board Computer. Rev. Sci. Instrum. 2020. [CrossRef] [PubMed]

15. Harper, M.M.; McKeating, K.S.; Faulds, K. Recent Developments and Future Directions in SERS for Bioanalysis. Phys. Chem. Chem. Phys. 2013, 15, 5312-5328. [CrossRef]

16. Li, Z.; Huang, X.; Lu, G. Recent Developments of Flexible and Transparent SERS Substrates. J. Mater. Chem. C 2020, 8, 3956-3969. [CrossRef]

17. Restaino, S.M.; White, I.M. A Critical Review of Flexible and Porous SERS Sensors for Analytical Chemistry at the Point-of-Sample. Anal. Chim. Acta 2019, 1060, 17-29. [CrossRef] [PubMed]

18. Le Ru, E.C.; Etchegoin, P.G. A Quick Overview of Surface-Enhanced Raman Spectroscopy. Princ. Surface-Enhanc. Raman Spectrosc. 2009, 1-27. [CrossRef]

19. Petti, L.; Capasso, R.; Rippa, M.; Pannico, M.; Lamanna, P.; Peluso, G.; Calarco, A.; Bobeico, E.; Musto, P. A Plasmonic Nanostructure Fabricated by Electron Beam Lithography as a Sensitive and Highly Homogeneous SERS Substrate for Bio-sensing Applications. Vib. Spectrosc. 2015, 82. [CrossRef]

20. Wang, Y.; Lu, N.; Wang, W.; Liu, L.; Feng, L.; Zeng, Z.; Li, H.; Xu, W.; Wu, Z.; Hu, W.; et al. Highly Effective and Reproducible Surface-Enhanced Raman Scattering Substrates Based on Ag Pyramidal Arrays. Nano Res. 2013, 6, 159-166. [CrossRef]

21. Ma, Y.; Zhou, J.; Zou, W.; Jia, Z.; Petti, L.; Mormile, P. Localized Surface Plasmon Resonance and Surface Enhanced Raman Scattering Responses of Au@Ag Core-Shell Nanorods with Different Thickness of Ag Shell. J. Nanosci. Nanotechnol. 2014, 14, 4245-4250. [CrossRef]

22. Olson, A.P.; Spies, K.B.; Browning, A.C.; Soneral, P.A.G.; Lindquist, N.C. Chemically Imaging Bacteria with Super-Resolution SERS on Ultra-Thin Silver Substrates. Sci. Rep. 2017. [CrossRef]

23. Rippa, M.; Castagna, R.; Pannico, M.; Musto, P.; Tkachenko, V.; Zhou, J.; Petti, L. Engineered Plasmonic Thue-Morse Nanostructures for LSPR Detection of the Pesticide Thiram. Nanophotonics 2017, 6, 1083-1092. [CrossRef]

24. Farooq, U.; Yang, Q.; Ullah, M.W.; Wang, S. Bacterial Biosensing: Recent Advances in Phage-Based Bioassays and Biosensors. Biosens. Bioelectron. 2018, 118, 204-216. [CrossRef]

25. Nobrega, F.L.; Vlot, M.; de Jonge, P.A.; Dreesens, L.L.; Beaumont, H.J.E.; Lavigne, R.; Dutilh, B.E.; Brouns, S.J.J. Targeting mechanisms of tailed bacteriophages. Nat. Rev. Microbiol. 2018, 16, 760-773. [CrossRef] [PubMed]

26. Droževkina, M.S. The present position in Brucella phage research. Bull. World Health Organ. 1963, $29,43-57$.

27. Liang, Z.; Zhou, J.; Petti, L.; Shao, L.; Jiang, T.; Qing, Y.; Xie, S.; Wu, G.; Mormile, P. SERS-Based Cascade Amplification Bioassay Protocol of MiRNA-21 by Using Sandwich Structure with Biotin-Streptavidin System. Analyst 2019. [CrossRef]

28. Rippa, M.; Castagna, R.; Zhou, J.; Paradiso, R.; Borriello, G.; Bobeico, E.; Petti, L. Dodecagonal Plasmonic Quasicrystals for Phage-Based Biosensing. Nanotechnology 2018, 29. [CrossRef]

29. Dal Negro, L.; Boriskina, S.V. Deterministic Aperiodic Nanostructures for Photonics and Plasmonics Applications. Laser Photonics Rev. 2012, 6, 178-218. [CrossRef]

30. Chen, D.; Zhou, J.; Rippa, M.; Petti, L. Structure-Dependent Localized Surface Plasmon Resonance Characteristics and Surface Enhanced Raman Scattering Performances of Quasi-Periodic Nanoarrays: Measurements and Analysis. J. Appl. Phys. 2015, 118. [CrossRef]

31. Matarazzo, V.; De Nicola, S.; Zito, G.; Mormile, P.; Rippa, M.; Abbate, G.; Zhou, J.; Petti, L. Spectral Characterization of Two-Dimensional Thue-Morse Quasicrystals Realized with High Resolution Lithography. J. Opt. 2011, 13. [CrossRef] 
32. Dal Negro, L.; Stolfi, M.; Yi, Y.; Michel, J.; Duan, X.; Kimerling, L.C.; LeBlanc, J.; Haavisto, J. Photon band gap properties and omnidirectional reflectance in $\mathrm{Si} / \mathrm{SiO} 2$ Thue-Morse quasicrystals. Appl. Phys. Lett. 2004, 84, 5186. [CrossRef]

33. Rippa, M.; Capasso, R.; Mormile, P.; De Nicola, S.; Zanella, M.; Manna, L.; Nenna, G.; Petti, L. Bragg extraction of light in 2D photonic thue-morse quasicrystals patterned in active CdSe/CdS nanorod-polymer nanocomposites. Nanoscale $2013,5,331$. [CrossRef] [PubMed]

34. Moretti, L.; Mocella, V. The square Thue-Morse tiling for photonic application. Philos. Mag. 2008, 88, 2275. [CrossRef]

35. Zhang, H.F.; Liu, S.B.; Kong, X.K. Enlarged the omnidirectional band gap in one-dimensional plasma photonic crystals with ternary Thue-Morse aperiodic structure. Physica B 2013, 410, 244. [CrossRef]

36. Gopinath, A.; Boriskina, S.V.; Reinhard, B.M.; Dal Negro, L. Deterministic Aperiodic Arrays of Metal Nanoparticles for SurfaceEnhanced Raman Scattering (SERS). Opt. Express 2009, 17, 3741. [CrossRef] [PubMed]

37. Lee, S.Y.K.; Amsden, J.J.; Boriskina, S.V.; Gopinath, A.; Mitropoulos, A.; Kaplan, D.L.; Omenetto, F.G.; Dal Negro, L. Spatial and spectral detection of protein monolayers with deterministic aperiodic arrays of metal nanoparticles. Proc. Natl. Acad. Sci. USA 2010, 107, 12086. [CrossRef] [PubMed]

38. Gopinath, A.; Boriskina, V.S.; Feng, N.-N.; Reinhard, B.M.; Dal Negro, L. Photonic-Plasmonic Scattering Resonances in Deterministic Aperiodic Structures. Nano Lett. 2008, 8, 2423-2431. [CrossRef] [PubMed]

39. Rippa, M.; Castagna, R.; Pannico, M.; Musto, P.; Bobeico, E.; Zhou, J.; Petti, L. Plasmonic Nanocavities-Based Aperiodic Crystal for Protein-Protein Recognition SERS Sensors. Opt. Data Process. Storage 2017, 3, 54-60. [CrossRef]

40. Rippa, M.; Castagna, R.; Pannico, M.; Musto, P.; Bobeico, E.; Zhou, J.; Petti, L. High-Performance Nanocavities-Based MetaCrystals for Enhanced Plasmonic Sensing. Opt. Data Process. Storage 2016, 2. [CrossRef]

41. Sambrook, J.; Russell, D.W.M. Molecular Cloning: A Laboratory Manual; CSHL Press: New York, NY, USA, 2001.

42. Domenici, F.; Bizzarri, A.R.; Cannistraro, S. Surface-Enhanced Raman Scattering Detection of Wild-Type and Mutant P53 Proteins at Very Low Concentration in Human Serum. Anal. Biochem. 2012. [CrossRef]

43. Hauer, P.; Grand, J.; Djorovic, A.; Willmott, G.R.; Le Ru, E.C. Spot Size Engineering in Microscope-Based Laser Spectroscopy. J. Phys. Chem. C 2016, 120, 21104-21113. [CrossRef]

44. Srivastava, S.K.; Hamo, H.B.; Kushmaro, A.; Marks, R.S.; Grüner, C.; Rauschenbach, B.; Abdulhalim, I. Highly sensitive and specific detection of $E$. coli by a SERS nanobiosensor chip utilizing metallic nanosculptured thin films. Analyst 2015, 140, 3201-3209. [CrossRef] [PubMed]

45. Kalele, S.A.; Kundu, A.A.; Gosavi, S.W.; Deobagkar, D.N.; Deobagkar, D.D.; Kulkarni, S.K. Rapid detection of Escherichia coli by using antibody-conjugated silver nanoshells. Small 2006, 2, 335-338. [CrossRef] 